\title{
Equilibrium Studies of the Sequential Removal of Reactive Blue 19 Dye and Lead (II) on Rapeseed Waste
}

\section{IRINA MOROSANU, LAVINIA TOFAN, CARMEN TEODOSIU*, CARMEN PADURARU}

"Gheorghe Asachi" Technical University of Iasi, "Cristofor Simionescu" Faculty of Chemical Engineering and Environmental Protection, Department of Environmental Engineering and Management, 73 Prof. D. Mangeron Str., 700050, Iasi, Romania

\begin{abstract}
This study investigates the effect of pollutant initial concentration on the sequential biosorptive removal of Reactive blue 19 dye and Pb(II) ions on rapeseed waste. The initial concentrations of both organic and inorganic pollutants positively influence the sequential biosorption of the dye and metal ion under study on rapeseed meal waste. The most significant increase was found in the removal of Reactive blue 19 dye by using rapeseed previously loaded with lead ions. In this case, the increase of the initial concentration from $15 \mathrm{mg} / \mathrm{L}$ to $100 \mathrm{mg} / \mathrm{L}$ results in an increase of the biosorption capacity of almost 6.8 times. Taking into account the frequent quantification of the wastewater treatment efficiency through the biosorption capacity generated from equilibrium studies, the obtained experimental data have been modelled by using five two-parameters (Langmuir, Freundlich, Halsey, Temkin and Harkins-Jura) and five three-parameters (Sips, Redlich-Peterson, Toth, modified BET and Hill) nonlinear isotherms. Linearized forms of Langmuir and Freundlich were also discussed. The optimal description for the sequential biosorption of the reactive dye is provided by the Hill and Langmuir isotherms, whereas the retention of lead on rapeseed waste is provided by the Freundlich isotherm.
\end{abstract}

Keywords: sequential, biosorption, isotherm, nonlinear, rapeseed waste

\section{Introduction}

Among the variety of pollutants existing in wastewaters, the heavy metals and dyes are of high prominence. The concern on these pollutants' presence in aquatic environments and consequently, the great interest on their removal are associated with their toxicity, mutagenic and carcinogenic effects. Sorption by low-cost materials from renewable resources is recognized as a promising and sustainable method for inorganic and organic pollutants removal. In this context, the high number of papers reporting the performances of natural and waste materials in the sorption of either heavy metals or dyes from mono-component aqueous solutions should be mentioned [1-7]. However, the coexistence of heavy metals and dyes in many effluents, as a result of the activity of different industries and/or an unsatisfactory management of wastewaters, imposes a focus on sorption studies in multi-component aqueous solutions, which much better simulate real wastewaters. The limited number of studies existing on these topics is steadily increasing. A significant part of them highlighted especially the efficient removal of both heavy metal ion, e.g. $\mathrm{Pb}(\mathrm{II}), \mathrm{Cu}(\mathrm{II}), \mathrm{Cd}(\mathrm{II})$, etc., and various dyes from binary solutions by their simultaneous or sequential retention on various sorbents, such as: hickory chips, cotton stalks, peanut hulls, hydrothermally modified fly ash, pre-treated $S$. cerevisiae, citric acid modified pine sawdust, treated mango leaves [8-11]. Unlike the simultaneous sorption, the sequential approach gives the opportunity to add value to a waste represented by the sorbent loaded with one of the pollutant which is recycled as new sorptive material for the other pollutant [12].

From this perspective, this study is oriented towards the equilibrium aspects of both cases of sequential biosorption on rapeseed waste (RS): $\mathrm{Pb}(\mathrm{II}) /$ Reactive blue 19 (Rb19) and $\mathrm{Rb} 19 / \mathrm{Pb}(\mathrm{II})$, respectively (Figure 1). Taking into account the primordial importance of the pollutant concentration in multi-component systems, a special attention is paid to the effects of $\mathrm{Pb}$ (II) and reactive blue dye initial concentrations on the proposed sequential sorption process.

\footnotetext{
*email:cteo@ch.tuiasi.ro
} 
Our research team has already gained experience in investigating rapeseed waste performances for the sorption removal of either heavy metal ions or textile dyes from mono-component aqueous solutions [13-15]. Besides, a recent study describes the RS behaviour through an integrated approach by combining experimental assessment and statistical modelling, with regards to the sequential sorption of $\mathrm{Pb}$ (II) ions and Reactive blue 19 dye from aqueous solutions [16]. The study finds that the sequential retention of the targeted pollutants could represent an option for a low-cost sorbent with a limited regeneration capacity caused by chemisorption or degradation after multiple sorptiondesorption cycles. For deepening this research, in this work an accurate mathematical description of the sequential sorption isotherms of $\mathrm{Pb}$ (II) ions and Reactive Blue 19 dye on rapeseed waste has been performed.

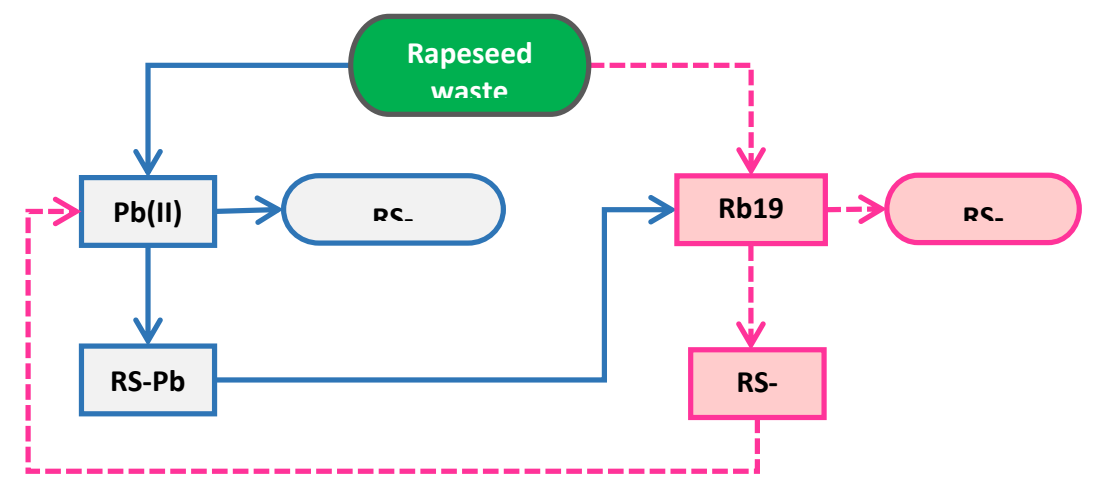

Figure 1. Schematic representation of the sequential processes of $\mathrm{Pb}(\mathrm{II})$ and Reactive Blue 19 dye sorption on rapeseed waste

\section{Materials and methods}

\subsection{Materials}

The sorbent, namely rapeseed waste (RS) provided by a local unit of biodiesel production has been prepared as follows: washing $\rightarrow$ drying $\left(40^{\circ} \mathrm{C}, 24 \mathrm{~h}\right) \rightarrow$ grinding $(0.1-0.2 \mathrm{~mm}) \rightarrow$ keeping in a desiccator for sorption studies $[14,15]$.

By dissolution of proper amounts of $\mathrm{Pb}\left(\mathrm{NO}_{3}\right)_{2}$ and Reactive blue 19 dye (analytical grade) in deionized water, stock solutions with a $1 \mathrm{~g} / \mathrm{L}$ concentration in the targeted pollutants have been prepared. The stock solutions dilution provided the working solutions.

\subsection{Batch sequential sorption}

The batch experiments of sequential sorption have been conducted in 2 stages, according to the procedure presented in Figure 2. In short, biosorption of lead ions and blue dye, respectively, was carried out on different samples of RS, in optimum conditions developed in [14] and [15] (liquid-tosolid ratio: $10 \mathrm{~g} / \mathrm{L}$, temperature: $20 \pm 1^{\circ} \mathrm{C}$, contact time: $180 \mathrm{~min}$. for $\mathrm{Pb}(\mathrm{II})$ and $240 \mathrm{~min}$. for $\mathrm{Rb} 19$, respectively). The sorbents loaded with lead ions (RS-Pb) and reactive dye (RS-Rb19), respectively thus obtained were then dried for $2 \mathrm{~h}$ at $30^{\circ} \mathrm{C}$ and left overnight at room temperature. $\mathrm{RS}-\mathrm{Pb}$ was further used for the removal of dye from aqueous media, while RS-Rb19 was contacted with solutions containing $\mathrm{Pb}(\mathrm{II})$ ions. The pollutants' concentrations varied in the range $15-125 \mathrm{mg} / \mathrm{L}$ and the phases were left until equilibrium reaching. The other experimental conditions, i.e. liquid-to-solid ratio and temperature, were maintained as for the mono-component biosorption tests.

Before and after each sorption experiment, the initial and equilibrium concentration of $\mathrm{Pb}(\mathrm{II})$ ions and Reactive Blue 19 dye have been determined by atomic absorption spectrometry (Buck Scientific atomic absorption spectrometer, $\lambda=283.3 \mathrm{~nm}$ ) and $\mathrm{UV}-\mathrm{V}$ is spectrophotometry (Jasco UV-Vis spectrophotometer, $\lambda=590 \mathrm{~nm})$, respectively.

Pollutant solubilisation (desorption) was expressed as the amount of pollutant $X$ leached in solution from the biosorbent after biosorption, in percentage, considering eq. 1 [17]: 


$$
\text { Desorbed } \mathrm{X}, \%=\frac{\mathrm{C}_{\mathrm{sol}}}{\mathrm{C}_{\text {bios }}} * 100
$$

where: $C_{\text {sol }}$ and $C_{\text {bios }}$ are the concentrations of the solubilized and respectively, biosorbed pollutant (expressed as difference between the initial and equilibrium concentration from the biosorption tests), in $\mathrm{mg} / \mathrm{L}$.

In this work, several two- and three-parameter isotherm models were applied to model the equilibrium data: Freundlich [18], Langmuir [19], Halsey [20], Temkin [21], Harkins-Jura [22], Sips [23], Redlich-Peterson [24], Toth [25], modified Brunauer-Emmett-Teller (BET) [26] and Hill [27].

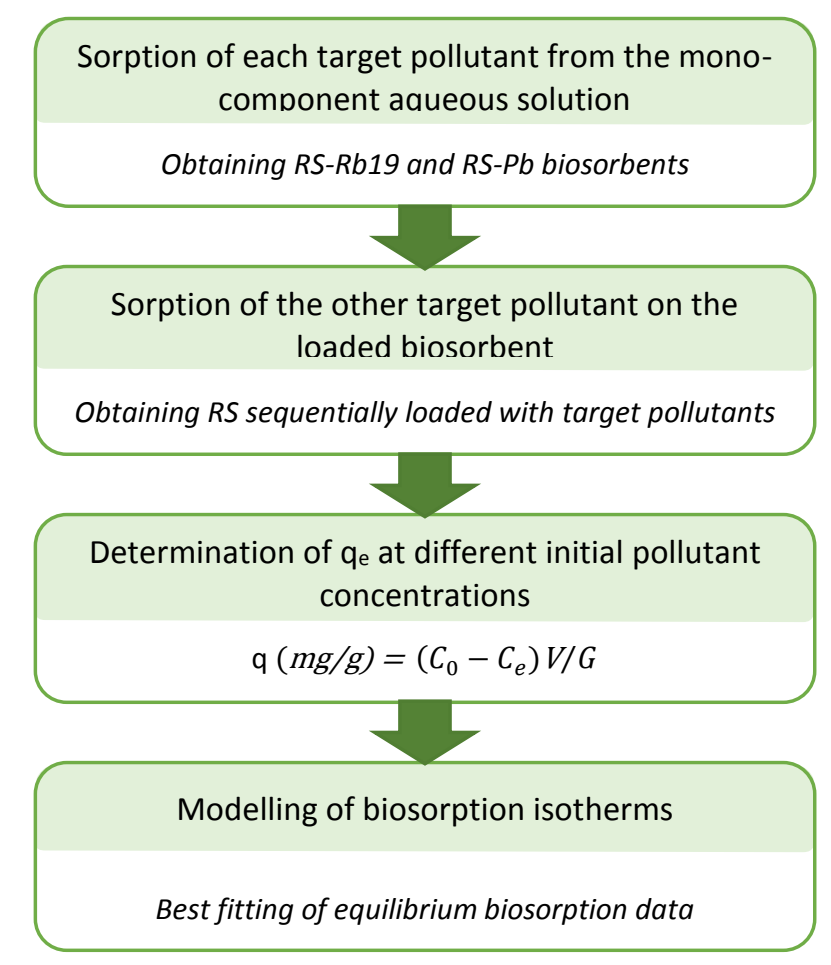

Figure 2. Block diagram of sequential biosorption experimental design

\subsection{Error analysis}

Statistical analysis of the goodness of fit of the predicted values by different isotherm equations with the experimental data was realised by using the coefficient of determination, $R^{2}$, and chi-square test $\left(\chi^{2}\right)$. The closeness between the data obtained using a model and the observed data is verified by obtaining $R^{2}$ values close to 1 and $\chi^{2}$ values close to 0 [28]. In this way, the best-fit isotherm can be identified for the biosorption system. The equations of the two types of error analysis are as follows [29]:

$$
\begin{aligned}
& \mathrm{R}^{2}=\frac{\sum\left(\mathrm{q}_{\mathrm{e}, \mathrm{m}}-\overline{\mathrm{q}_{\mathrm{e}}}\right)^{2}}{\sum\left(\mathrm{q}_{\mathrm{e}, \mathrm{m}}-\overline{\mathrm{q}_{\mathrm{e}}}\right)^{2}+\sum\left(\mathrm{q}_{\mathrm{m}}-\mathrm{q}_{\mathrm{e}}\right)^{2}} \\
& \chi^{2}=\sum \frac{\left(\mathrm{q}_{\mathrm{e}}-\mathrm{q}_{\mathrm{e}, \mathrm{m}}\right)^{2}}{\mathrm{q}_{\mathrm{e}, \mathrm{m}}}
\end{aligned}
$$

where: $q_{\mathrm{e}}(\mathrm{mg} / \mathrm{g})$ - experimental biosorption capacity at equilibrium, $q_{\mathrm{e}, \mathrm{m}}(\mathrm{mg} / \mathrm{g})$ - modelled (predicted) biosorption capacity, $\overline{q_{\mathrm{e}}}(\mathrm{mg} / \mathrm{g})$ - average of experimental $q_{\mathrm{e}}$ values.

The parameters of biosorption isotherms were determined by nonlinear regression analysis. The nonlinear equations were computed using the Solver add-in function of the Microsoft Excel, by maximizing the coefficient of determination while minimizing the chi-square test values. For two widely used isotherms, Langmuir and Freundlich, the linear regression analysis was also discussed.

In order to provide useful data for the design of the sequential biosorption process as unit 
operation, the study has been performed in two stages. The first stage deals with the effect of initial dye concentration and initial metal ion concentration on the sequential biosorptive removal of pollutants. The second stage is focused on the sequential biosorption equilibrium description by means of the most relevant isotherm models.

\subsection{Effect of initial concentration}

The influence of the initial concentration on the sequential removal of the inorganic and respectively, organic pollutant is presented in Figure 3. For comparison, the uptakes obtained in the biosorption process on pristine RS are also illustrated. In the case of metal ions removal by RS-Rb19, the biosorption capacity increased with concentration, from $3.12 \mathrm{mg} / \mathrm{g}$ at $25 \mathrm{mg} / \mathrm{L}$ to $12.26 \mathrm{mg} / \mathrm{g}$ for $125 \mathrm{mg} / \mathrm{L}$. As against the biosorption on the pristine RS, the data indicate a slight improvement of the process at low concentrations $(<50 \mathrm{mg} / \mathrm{L})$, while the process efficiency seems to decrease at higher concentrations (Figure 3a). According to Figure 3b, a positive effect of the initial concentration was also observed when $\mathrm{RS}-\mathrm{Pb}$ was used for the removal of the anthraquinone dye from solution, the biosorption capacity reaching a value of $8.76 \mathrm{mg} / \mathrm{g}$ at $100 \mathrm{mg} / \mathrm{L}$. The difference of the amount of dye between the liquid and solid phases constitutes a significant driving force for the biosorption process. However, when compared to the individual biosorption of the same pollutant, there was an increase in the biosorption efficiency over all concentration range (15-100 $\mathrm{mg} \mathrm{Rb} 19 / \mathrm{L})$. At the solution $\mathrm{pH} 5-6$, both pollutants are present in the liquid phase in their ionized forms, having opposite charges. This would suggest a biosorption based on electrostatic interactions.

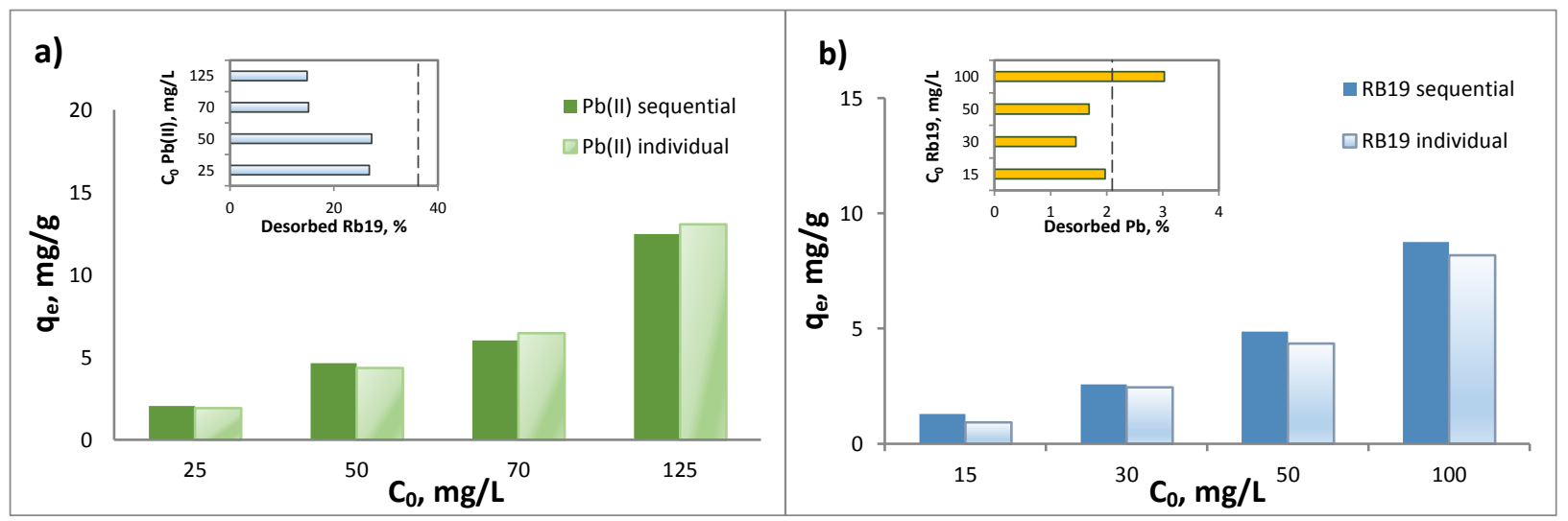

Figure 3. Influence of initial concentration on the sequential biosorption of lead ions (a) and

Rb19 dye (b) and pollutant solubilization (inset) (dotted line indicates solubilization in water)

The solubilisation of lead ions was observed at the end of biosorption experiments. As presented in the inset of Figure 3b, the amount of lead ions present in dye solutions with initial concentrations of $15-50 \mathrm{mg} / \mathrm{L}$ was smaller than the one obtained when using ultrapure water. This observation, along with higher values of $q_{\mathrm{Rb} 19}$ in the sequential biosorption process, indicate a conditioning of the biosorptive substrate by creating new active centers due to the presence of lead ions. According to the results of the biosorption study of $\mathrm{Pb}$ (II) ions on $\mathrm{RS}$ [15], the uptake of the metal ions took place in monolayer, respecting the assumptions of the Langmuir isotherm model.

At higher concentrations (e.g. $100 \mathrm{mg} / \mathrm{L}$ ), it may be also possible that the larger Rb19 dye molecules $\left(\mathrm{M}_{\mathrm{Rb} 19}=626.54 \mathrm{~g} / \mathrm{mol}\right)$ could replace some of the metal ions from the RS-Pb surface, resulting in larger amounts of lead in the solution at the end of the experimental run. Even so, the desorbed quantity of lead ions is under $3 \%$ and can be considered negligible.

\subsection{Sequential biosorption isotherms}

An adequate design of a biosorption process requires the fundamental information offered by the biosorption isotherms, which indicate the distribution of the pollutant between the aqueous and solid 
phases when the equilibrium conditions are met. In particular, the equation of a biosorption isotherm describes the dependence between the amount of species biosorbed per mass unit of biosorbent $\left(\mathrm{q}_{\mathrm{e}}\right)$ and its residual equilibrium concentration in the solution phase $\left(C_{e}\right)$. In this study, the equilibrium data was modelled according to the equations of different isotherms, with two parameters (Langmuir, Freundlich, Halsey and Temkin) and three parameters (Sips, Redlich-Peterson, Toth and BrunauerEmmett-Teller).The nonlinear regression models' parameters were optimized by adopting an error minimization procedure that implied to simultaneously maximize the coefficient of determination $\left(R^{2}\right)$ and minimize the Chi-square $\left(\chi^{2}\right)$ values by using Excel Solver. The isotherm equations and parameters, as well as the statistical analysis, are presented in Table 1 and Table 3 for two- and threeparameter isotherm models previously mentioned. Figure 4 displays the experimental and modelled biosorption isotherms for $\mathrm{Pb}(\mathrm{II})$ ions and $\mathrm{Rb} 19$ dye.

With a vital role in the quantification and comparison of biosorbent performances, Langmuir isotherm has three fundamental assumptions which involve: the sorption limitation to a coverage in monolayer, the homogeneity of all surface sites, being able to host only one retained atom, and the independence of the molecule's ability to be retained on a given site to the occupancy of its adjacent sites $[7,30]$. The relevance of Langmuir nonlinear model to describe the sequential biosorption of the other target pollutant by $\mathrm{RS}-\mathrm{Pb}$ is guaranteed by the high values of the $R^{2}$ coefficient and low values of the $\chi^{2}$ test, as presented in Table 1. Smaller values for the Langmuir parameters were obtained for dye sequential biosorption than for lead sequential biosorption, suggesting lower sorption energy and weaker sorbate-sorbent interactions.

By means of Langmuir equilibrium constant, a dimensionless separation factor, i.e. $R_{\mathrm{L}}$, can be calculated [31]:

$$
R_{L}=\frac{1}{1+K_{L} C_{0}}
$$

The sequential biosorption process is favourable if $R_{\mathrm{L}}$ is in the range 0 to 1 , while $R_{\mathrm{L}}>1, R_{\mathrm{L}}=1$ or $R_{\mathrm{L}}=0$ describe an unfavourable, linear and respectively, irreversible process [30]. In this study, the factor $R_{\mathrm{L}}$ varies between 0.6586 and 0.2099 for Rb19 sequential biosorption and 0.1304 and 0.0363 for lead ions biosorption.

The heat of biosorption decreases with the increasing degree of site occupation [32]. This is well described by Freundlich isotherm, which also characterizes processes of reversible and multilayer sorption in heterogeneous systems, particularly for organic compounds or highly interactive species [8,33]. The magnitude of the exponent $n$ indicates the favourability of the uptake: $n$ between 2 and 10 represent good, 1-2 moderately difficult and $<1$ poor biosorption characteristics [32]. Values of parameter $n$ between 1 and 2 (Table 1) show that the two sequential biosorption systems under study are characterized by a certain degree of difficulty regarding the solutes' uptake. The higher value of Freundlich equilibrium constant, $K_{\mathrm{F}}$, for the $\mathrm{Pb}(\mathrm{II})$ sequential biosorption in contrast to dye removal (Table 1) is attributed to a high affinity of the sorbent to the pollutant. Based on the error function estimates, the nonlinear Freundlich model describes well the sequential biosorption of $\mathrm{Pb}$ (II) ions.

In view of the extensive use of the Langmuir and Freundlich linear isotherm models for modelling of the equilibrium biosorption data, a comparison between the nonlinear and linearized equations was done for the sequential biosorption. The results obtained for the linearized models are presented in Table 2. It was reported the linearization of isotherm equations erroneous parameters and that the nonlinear method is required to obtain correct parameters [28,34]. In this study, the Langmuir-1 form provided the best agreement with the experimental data, for both sequential biosorption systems among the linearized Langmuir models, according to Table 2 and the closeness with the nonlinear parameters $q_{\mathrm{m}}$ and $K_{\mathrm{L}}$. The error propagation due to linearization caused large discrepancy for Langmuir-2 parameters in case of Rb19, evidenced by the difference in the $\chi^{2}$-test values of one order of magnitude. Langmuir-3 and Langmuir-4 forms present the poorest applicability among the linearized Langmuir model equations. On the other hand, linearization of Freundlich isotherm didn't result in significant differences when compared to the nonlinear parameters. 
Nevertheless, the trend of the isotherm fitness remained the same as for nonlinear models. It can be clearly observed from Table 2 the better agreement between the observed and calculated data derived from Langmuir isotherm in the case of dye sequential biosorption and from Freundlich model for lead sequential biosorption.
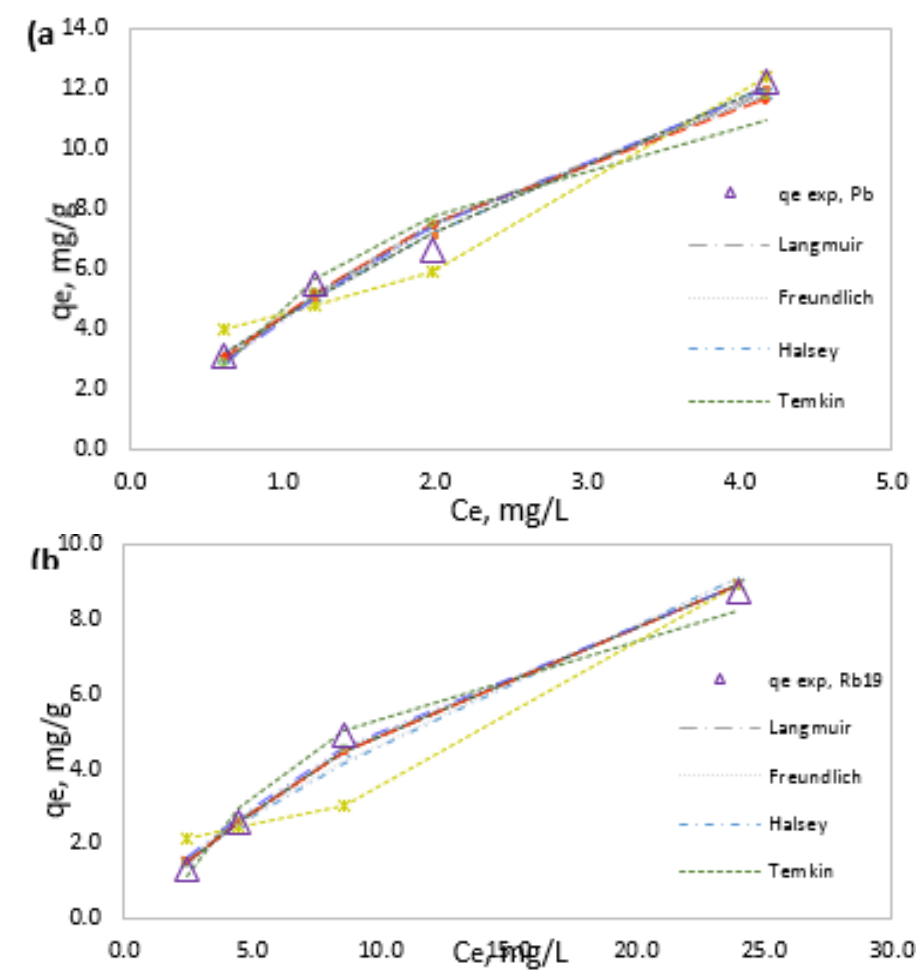

Figure 4. Equilibrium isotherms for the sequential biosorption process of $\mathrm{Pb}(\mathrm{II})$ ions (a) and Rb19 dye (b)

Table 1. Two-parameter biosorption isotherm models and obtained parameters for lead ions and reactive dye

\begin{tabular}{|c|c|c|c|c|}
\hline Model & Equation* & Parameters & $\mathbf{P b}(\mathrm{II})$ & Rb19 \\
\hline \multirow[t]{4}{*}{ Langmuir } & $\mathrm{q}_{\mathrm{m}} \mathrm{K}_{\mathrm{L}} \mathrm{C}_{\mathrm{e}}$ & $q_{\mathrm{m}}(\mathrm{mg} / \mathrm{g})$ & 25.5585 & 19.9274 \\
\hline & $\mathrm{q}_{\mathrm{e}}=\frac{\mathrm{Im}_{\mathrm{m}}}{1+\mathrm{K}_{\mathrm{I}} \mathrm{C}_{\mathrm{e}}}$ & $K_{\mathrm{L}}(\mathrm{L} / \mathrm{mg})$ & 0.2096 & 0.0337 \\
\hline & $1+\mathbf{\Lambda}_{\mathrm{L}} \mathrm{C}_{\mathrm{e}}$ & $R^{2}$ & 0.9772 & 0.9925 \\
\hline & & $\chi^{2}$ & 0.1441 & 0.0762 \\
\hline \multirow[t]{4}{*}{ Freundlich } & $\mathrm{q}_{\mathrm{e}}=\mathrm{K}_{\mathrm{F}} \mathrm{C}_{\mathrm{e}}^{1 / \mathrm{n}}$ & $n$ & 1.4271 & 1.3284 \\
\hline & & $K_{\mathrm{F}}(\mathrm{mg} / \mathrm{g})(\mathrm{L} / \mathrm{mg})^{1 / n}$ & 4.4403 & 0.8354 \\
\hline & & $R^{2}$ & 0.9886 & 0.9793 \\
\hline & & $\chi^{2}$ & 0.0784 & 0.1962 \\
\hline \multirow[t]{4}{*}{ Halsey } & $\mathrm{q}_{\mathrm{e}}=\mathrm{e}^{\left(\ln \mathrm{K}_{\mathrm{H}^{-}} \ln \mathrm{C}_{\mathrm{e}}\right) / \mathrm{n}_{\mathrm{H}}}$ & $n_{\mathrm{H}}$ & -1.4214 & -1.2977 \\
\hline & & $K_{\mathrm{H}}(\mathrm{L} / \mathrm{mg})$ & 0.1213 & 1.3664 \\
\hline & & $R^{2}$ & 0.9886 & 0.9778 \\
\hline & & $\chi^{2}$ & 0.0793 & 0.1957 \\
\hline \multirow[t]{4}{*}{ Temkin } & $\left.\mathrm{RT}_{\ln (\mathrm{K}} \mathrm{C}\right)$ & $\mathrm{b}_{T}(\mathrm{~kJ} / \mathrm{mol})$ & 0.5727 & 0.7761 \\
\hline & $\mathrm{q}_{\mathrm{e}}=\frac{-}{\mathrm{b}_{\mathrm{T}}} \ln \left(\mathrm{K}_{\mathrm{T}} \mathrm{C}_{\mathrm{e}}\right)$ & $K_{\mathrm{T}}(\mathrm{L} / \mathrm{g})$ & 3.1285 & 0.5786 \\
\hline & & $R^{2}$ & 0.9159 & 0.9838 \\
\hline & & $\chi^{2}$ & 0.3802 & 0.1178 \\
\hline \multirow[t]{4}{*}{ Harkins-Jura } & $\left(\mathrm{A}_{\mathrm{HJ}}\right)^{0.5}$ & $A_{\mathrm{HJ}}(\mathrm{mg} / \mathrm{L})^{2}$ & 14.6572 & 4.5763 \\
\hline & $\mathrm{q}_{\mathrm{e}}=\left(\overline{\mathrm{B}_{U^{-}} \log \mathrm{C}}\right)$ & $B_{\mathrm{HJ}}(\mathrm{mg} / \mathrm{L})$ & 0.7156 & 1.4378 \\
\hline & & $R^{2}$ & 0.9630 & 0.8849 \\
\hline & & $\chi^{2}$ & 0.3937 & 1.2215 \\
\hline
\end{tabular}

Table 2. Comparison of obtained parameters derived from linear and nonlinear Langmuir and Freundlich isotherm equations 


\begin{tabular}{|c|c|c|c|c|c|}
\hline Model & Linearized equation & Plot & Parameter & $\mathbf{P b}(\mathrm{II})$ & Rb19 \\
\hline Langmuir-1 & $\frac{C_{e}}{q_{e}}=\frac{C_{e}}{q_{m}}+\frac{1}{K_{L} q_{m}}$ & $\frac{\mathrm{C}_{\mathrm{e}}}{\mathrm{q}_{\mathrm{e}}}$ vs. $\mathrm{C}_{\mathrm{e}}$ & $\begin{array}{c}q_{\mathrm{m}}(\mathrm{mg} / \mathrm{g}) \\
K_{\mathrm{L}}(\mathrm{L} / \mathrm{mg}) \\
R^{2} \\
\chi^{2}\end{array}$ & $\begin{array}{c}25.0650 \\
0.2152 \\
0.8733 \\
0.1443\end{array}$ & $\begin{array}{c}22.1765 \\
0.0283 \\
0.8541 \\
0.0912\end{array}$ \\
\hline Langmuir-2 & $\frac{1}{q_{e}}=\frac{1}{q_{m}}+\frac{1}{K_{L} q_{m}} \cdot \frac{1}{C_{e}}$ & $\frac{1}{q_{e}}$ vs. $\frac{1}{C_{e}}$ & $\begin{array}{c}q_{\mathrm{m}}(\mathrm{mg} / \mathrm{g}) \\
K_{\mathrm{L}}(\mathrm{L} / \mathrm{mg}) \\
R^{2} \\
\chi^{2}\end{array}$ & $\begin{array}{c}19.7282 \\
0.3026 \\
0.9874 \\
0.2323 \\
\end{array}$ & $\begin{array}{c}135.9683 \\
0.0040 \\
0.9895 \\
0.8668 \\
\end{array}$ \\
\hline Langmuir-3 & $\mathrm{q}_{\mathrm{e}}=\mathrm{q}_{\mathrm{m}}-\frac{1}{\mathrm{~K}_{\mathrm{L}}} \cdot \frac{\mathrm{q}_{\mathrm{e}}}{\mathrm{C}_{\mathrm{e}}}$ & $q_{e}$ vs. $\frac{q_{e}}{C_{e}}$ & $\begin{array}{c}q_{\mathrm{m}}(\mathrm{mg} / \mathrm{g}) \\
K_{\mathrm{L}}(\mathrm{L} / \mathrm{mg}) \\
R^{2} \\
\chi^{2} \\
\end{array}$ & $\begin{array}{c}20.7243 \\
0.2856 \\
0.7878 \\
1.0402 \\
\end{array}$ & $\begin{array}{c}17.8033 \\
0.0378 \\
0.6310 \\
3.3842 \\
\end{array}$ \\
\hline Langmuir-4 & $\frac{q_{e}}{C_{e}}=K_{L} q_{m}-K_{L} q_{e}$ & $\frac{\mathrm{q}_{\mathrm{e}}}{\mathrm{C}_{\mathrm{e}}}$ vs. $\mathrm{q}_{\mathrm{e}}$ & $\begin{array}{c}q_{\mathrm{m}}(\mathrm{mg} / \mathrm{g}) \\
K_{\mathrm{L}}(\mathrm{L} / \mathrm{mg}) \\
R^{2} \\
\chi^{2}\end{array}$ & $\begin{array}{c}24.4566 \\
0.2250 \\
0.7878 \\
0.3117\end{array}$ & $\begin{array}{c}25.6573 \\
0.0239 \\
0.6310 \\
0.1967\end{array}$ \\
\hline Freundlich & $\log q_{e}=\log K_{F}+\frac{1}{n} \log C_{e}$ & $\log q_{e}$ vs. $\log C_{e}$ & $\begin{array}{c}n \\
K_{\mathrm{F}}(\mathrm{mg} / \mathrm{g})(\mathrm{L} / \mathrm{mg})^{1 / n} \\
R^{2} \\
\chi^{2}\end{array}$ & $\begin{array}{l}1.4349 \\
4.4378 \\
0.9867 \\
0.0789\end{array}$ & $\begin{array}{l}1.1996 \\
0.6891 \\
0.9710 \\
0.2649\end{array}$ \\
\hline
\end{tabular}

Another exponential isotherm equation, Halsey model is suitable for characterizing a biosorption process that takes place in multiple layers at a relatively large distance from the heterogeneous surface $[29,35]$. In this way, Halsey isotherm is similar to Freundlich model, the reason why the coefficient of determination and at least one of the Halsey parameters are very close or even identical, being presented in [36-41]. In this research study, Figure 4a reveals the similarity between the shapes of the two isotherms for both sequential biosorption systems. This is more evidently for lead, where the values of the exponent are very close and $R^{2}$ coefficients are identical (Table 1). However, Freundlich isotherm model is a better fit, because of the lower Chi-square values obtained.

The Temkin isotherm model considers the interaction between the solute and sorbent, which causes a linear decreasing of biosorption heat with coverage rather than logarithmic [33]. It is implied by its equation exhibited in Table 1 that biding energies are uniformly distributed [30]. The Temkin parameter $b_{\mathrm{T}}$ indicates the variation of the biosorption energy, which is higher in case of Rb19 uptake, showing stronger interactions with the biosorbent compared to metal biosorption. Also for this case, the Temkin model provided a better fit to the experimental data (Table 1, Figure 4a).

Harkins-Jura isotherm is another model assuming multilayer biosorption and a heterogeneous distribution of active sites [29]. As the tabulated results of error analysis show, this isotherm describes unsatisfactorily both lead and Rb19 dye equilibrium data (Table 1).

The abilities of three-parameter isotherms, namely Sips, Redlich-Peterson, Toth, modified BET and Hill, to model the equilibrium data of the two sequential biosorption systems under investigation were also examined. The resulting curves and parameters are presented in Figure $4 \mathrm{~b}$ and Table 3.

The first two three-parameter isotherms previously mentioned combine the characteristics of both Langmuir and Freundlich models. Sips equation was formulated for predicting the heterogeneous biosorption process, when the sorbate interacts with only one active site, creating a monolayer [42]. At low $C_{\mathrm{e}}$ values, Sips isotherm reduces to Freundlich model, while at high concentration values it approaches the Langmuir isotherm. The dimensionless exponent $s$ of Sips equation (Table 3) quantitatively describes the heterogeneity of the sorbate-biosorbent system and is usually in the range $0-1$. When this parameter is equal to unity, this equation will take the Langmuir form. Such is the case of Rb19 sequential biosorption in this investigation, which is in line with a much better fit of Langmuir isotherm rather than the Freundlich model. This affirmation is corroborated by the very close value of Sips maximum biosorption capacity $(20.43 \mathrm{mg} / \mathrm{g})$ with the Langmuir saturation capacity $(19.92 \mathrm{mg} / \mathrm{g})$. $\mathrm{Pb}$ (II) ions sequential biosorption presents some degree of heterogeneity, as denoted by the $s$ value in Table 3, not very far below unity. However, the error analysis indicates a relatively poor prediction of 
the laboratory data, suggesting that Sips isotherm does not allow for reliable assumptions for the sequential biosorption of $\mathrm{Pb}(\mathrm{II})$.

Table 3. Three-parameter biosorption isotherm models and obtained parameters for lead ions and reactive dye

\begin{tabular}{|c|c|c|c|c|}
\hline Model & Equation* & Parameters & $\mathbf{P b}(\mathrm{II})$ & Rb19 \\
\hline \multirow[t]{5}{*}{ Sips } & $\mathrm{q}_{\mathrm{S}} \mathrm{K}_{\mathrm{S}} \mathrm{C}_{\mathrm{e}}^{\mathrm{s}}$ & $q_{\mathrm{S}}(\mathrm{mg} / \mathrm{g})$ & 29.9476 & 20.4367 \\
\hline & $\mathrm{q}_{\mathrm{e}}=\frac{\mathrm{s} \mathrm{s}}{1+\mathrm{K}_{\mathrm{s}} \mathrm{C}_{\mathrm{s}}^{\mathrm{s}}}$ & $K_{\mathrm{S}}(\mathrm{L} / \mathrm{mg})$ & 0.1736 & 0.0322 \\
\hline & & $s$ & 0.9255 & 1.0000 \\
\hline & & $R^{2}$ & 0.9788 & 0.9918 \\
\hline & & $\chi^{2}$ & 0.1306 & 0.0789 \\
\hline \multirow[t]{5}{*}{ Redlich-Peterson } & $\mathrm{K}_{\mathrm{RP}} \mathrm{C}_{\mathrm{e}}$ & $K_{\mathrm{RP}}(\mathrm{L} / \mathrm{g})$ & 1243.69 & 0.6582 \\
\hline & $\mathrm{q}_{\mathrm{e}}=\frac{\overline{\mathrm{aC}^{\beta}}}{1+\mathrm{s}}$ & $a(\mathrm{~L} / \mathrm{mg})^{\beta}$ & 280.9027 & 0.0322 \\
\hline & & $\beta$ & 0.2974 & 1.0000 \\
\hline & & $R^{2}$ & 0.9886 & 0.9918 \\
\hline & & $\chi^{2}$ & 0.0793 & 0.0789 \\
\hline \multirow[t]{5}{*}{ Toth } & $\mathrm{q}_{\mathrm{T}_{0}} \mathrm{~K}_{\mathrm{To}} \mathrm{C}_{\mathrm{e}}$ & $q_{\mathrm{To}}(\mathrm{mg} / \mathrm{g})$ & 26.5378 & 20.4369 \\
\hline & $\mathrm{q}_{\mathrm{e}}=\frac{1 \mathrm{O}}{\left(1+\left(\mathrm{K}_{\mathrm{T}_{0}} \mathrm{C}_{\mathrm{e}}\right)^{\mathrm{t}}\right)^{1 / \mathrm{t}}}$ & $K_{\mathrm{To}}(\mathrm{L} / \mathrm{mg})$ & 0.2200 & 0.0322 \\
\hline & & $t$ & 0.8874 & 1.0000 \\
\hline & & $R^{2}$ & 0.9719 & 0.9918 \\
\hline & & $\chi^{2}$ & 0.1524 & 0.0789 \\
\hline \multirow[t]{5}{*}{ Modified BET } & $q_{B E T} K_{1} C_{e}$ & $q_{\text {BET }}(\mathrm{mg} / \mathrm{g})$ & 26.8400 & 18.4649 \\
\hline & $q_{e}=\overline{\left(1-K_{2} C_{e}\right)\left(1-K_{2} C_{e}+K_{1} C_{e}\right)}$ & $K_{1}(\mathrm{~L} / \mathrm{mg})$ & 0.1912 & 0.0383 \\
\hline & & $K_{2}(\mathrm{~L} / \mathrm{mg})$ & 0.0007 & 0.0003 \\
\hline & & $R^{2}$ & 0.9795 & 0.9931 \\
\hline & & $\chi^{2}$ & 0.1564 & 0.0989 \\
\hline \multirow[t]{5}{*}{ Hill } & $\mathrm{q}_{\mathrm{Hi}} \mathrm{C}_{\mathrm{e}}^{\mathrm{h}}$ & $q_{\mathrm{Hi}}(\mathrm{mg} / \mathrm{g})$ & 13400.41 & 11.6247 \\
\hline & $\mathrm{q}_{\mathrm{e}}=\frac{\mathrm{IHi}_{\mathrm{Hi}} \mathrm{e}}{\mathrm{K}_{\mathrm{H}}+\mathrm{C}^{\mathrm{h}}}$ & $h$ & 0.7039 & 1.4076 \\
\hline & $\mathrm{K}_{\mathrm{Hi}}+\mathrm{C}_{\mathrm{e}}^{11}$ & $K_{\mathrm{Hi}}$ & 3036.4036 & 28.6924 \\
\hline & & $R^{2}$ & 0.9886 & 1.0000 \\
\hline & & $\gamma^{2}$ & 0.0793 & $4.52 \cdot 10^{-5}$ \\
\hline
\end{tabular}

$q_{\mathrm{s}}, q_{\mathrm{To}}, q_{\mathrm{Hi}}-$ maximum biosorption capacity; $q_{\mathrm{BET}}$ - monolayer biosorption capacity, $C_{\mathrm{e}}-$ sorbate concentration at equilibrium;

$K_{\mathrm{S}}, K_{\mathrm{RP}}, K_{\mathrm{To}}, K_{\mathrm{Hi}}-$ equilibrium constants of the corresponding isotherm model; $K_{1}, K_{2}$ - equilibrium constant of biosorption for first and upper layers, respectively; $S, \beta, t, h$-corresponding isotherm model exponent; $a$-Redlich-Peterson isotherm constant.

Redlich-Peterson isotherm is an empirical model, with the ability to describe the equilibrium over a wide range of concentrations and it can be applicable in either homogenous or heterogeneous systems [29]. The reason can be found in the expression of its equation, by displaying a linear dependence in the numerator, and an exponential relation in the denominator (Table 3). At high concentrations of solute, the equation takes the Freundlich form. The exponent $\beta$ is a measure of the heterogeneity degree of the biosorbent $(0<\beta \leq 1)$. There are two limiting behaviours: for $\beta=1$ the equation predicts the Langmuir biosorption capacity, and for $\beta=0$ it follows the Henry's law of linear biosorption [43]. The graphical results in Figure $4 \mathrm{~b}$ and the tabulated goodness-of-fit statistics suggest the good compatibility of this isotherm model for both sequential biosorption systems studied. In this case, a $\beta$ value closer to zero reflects a pronounced heterogeneity of the lead-biosorbent system, much better than Sips isotherm. The sequential biosorption of the blue dye follows a monolayer homogeneous sorption, as indicated by $\beta=1$. In this case, $a$ parameter is equivalent to the Langmuir equilibrium constant, $K_{\mathrm{L}}$. Indeed, the values for the two parameters are close (Tables 2 and 3). By similitude, $K_{\mathrm{RP}}$ should then be equivalent to the product $q_{\mathrm{m}} K_{\mathrm{L}}$ from the numerator of Langmuir equation. By taking also in account the value of parameter $a$, the maximum biosorption capacity according to RedlichPeterson model would be $20.441 \mathrm{mg} / \mathrm{g}$, which is very similar to the Langmuir biosorption capacity shown in Table 1.

In order to reduce the error between the predicted and observed equilibrium points, Langmuir model was modified in the form of Toth equation [30]. This isotherm assumes a quasi-Gaussian energy distribution and is applicable for the heterogeneous systems at low and high concentrations $[29,44]$. Parameter $t$ is said to characterize the system heterogeneity: for $t=1$ the biosorption is homogeneous, while as $t$ is further bellow the unity, the more the system heterogeneity increases. Toth isotherm 
describes very well the Rb19 dye uptake on $\mathrm{RS}-\mathrm{Pb}$, indicating a homogenous process as a result of $t=$ 1 (Table 3). Yet again, Toth parameters $q_{\text {To }}$ and $K_{\text {To }}$ are similar to the ones of Langmuir model. On the other hand, Toth equation is not such a good fit for lead ions sequential biosorption based on the goodness-of-fit statistics in Table 3. As seen in Figure 4a, Toth isotherm curve fits better at low $\mathrm{Pb}$ (II) concentrations.

Brunauer-Emmett-Teller (BET) isotherm model is a special case of Langmuir isotherm, extended for the evaluation of multilayer sorption systems [35]. In order to apply BET isotherm to liquid phase sorption, Ebadi et al. [26] proposed a modification of BET classical equation, by including the equilibrium constants of the first and consecutive layers, namely $K_{1}$ and $K_{2}$ (modified BET equation in Table 3). The results of the goodness-of-fit statistics $R^{2}$ and $\chi^{2}$ in Table 3 indicate that the experimental data for $\mathrm{Pb} 19$ sequential biosorption was able to comply with this equation, but for the $\mathrm{Pb}$ (II) data was a relatively poor fit. In both cases, the monolayer BET biosorption capacity values are similar to the Langmuir saturation capacity values.

The Hill isotherm model explains the binding of different species on homogeneous substrates, assuming a cooperative interaction in which the binding at one site of the substrate could influence ligand binding at other sites in the vicinity [45]. This is expressed by the exponent of the equation: if $h$ $=1$, the biding is hyperbolic or non-cooperative, if $h>1$, there is a positive cooperative sorption, while negative cooperation takes place when $h<1$. Hill equation showed good compatibility with the equilibrium data derived for both pollutants under study, according to the error analysis results presented in Table 3 and the curves illustrated in Figure 4. While the $h$ value above 1 (Table 3) shows a positive cooperative sequential biosorption of $\mathrm{Rb} 19$, the binding of $\mathrm{Pb}$ (II) ions to the active sites on RS-Rb19 surface are inhibited by the interactions taking place in the vicinity (negative cooperation).

At a closer look, Hill isotherm equation is very similar to Langmuir equation. The latter can be derived from the former by dividing the Langmuir non-linear equation with the equilibrium constant $K_{\mathrm{L}}$ from Table 2 as follows:

$$
\mathrm{q}_{\mathrm{e}}=\frac{\mathrm{q}_{\mathrm{m}} \mathrm{C}_{\mathrm{e}}}{\frac{1}{\mathrm{~K}_{\mathrm{L}}}+\mathrm{C}_{\mathrm{e}}}
$$

Comparing with the Hill equation, it can be observed that: $\mathrm{K}_{\mathrm{D}} \equiv \frac{1}{\mathrm{~K}_{\mathrm{L}}}$ when $h=1$.

Now, if the optimization of Hill equation is done by setting $h=1$ as constraint (or $h \leq 1$ for Rb19 and $h \geq 1$ for lead), the optimal parameter values, presented in Table 4, are very close to the values for Langmuir equation (Table 2), in the detriment of a poorer fit.

Table 4. Optimal parameters of Hill isotherm equation when $h=1$

\begin{tabular}{cccccc}
\hline & $\boldsymbol{q H}_{\mathbf{H i}}$ & $\boldsymbol{K}_{\mathbf{H i}}$ & $\mathbf{1} / \boldsymbol{K}_{\mathbf{L}}$ & $\boldsymbol{R}^{\mathbf{2}}$ & $\boldsymbol{\chi}^{\mathbf{2}}$ \\
\hline $\mathrm{Pb}(\mathrm{II})$ & 25.8398 & 4.9122 & 4.7709 & 0.9776 & 0.1544 \\
\hline $\mathrm{Rb} 19$ & 20.4367 & 31.0498 & 29.6535 & 0.9918 & 0.0789 \\
\hline
\end{tabular}

The best-fitted isotherm model was established considering a nonlinear regression with high value of $R^{2}$ and, in the same time, a low value of $\chi^{2}$. As it is demonstrated in Table 1 and 3, the sequential biosorption of lead ions was found to be described, in the order of precision, as follows: Freundlich > Halsey $\approx$ Redlich-Peterson $\approx$ Hill $>$ Sips $>$ Langmuir $>$ Toth $>($ Hill for $h=1)>$ modified BET $>$ Harkins-Jura > Temkin. The application of the Freundlich isotherm as best fit supports the assumption of a mainly heterogeneous sequential biosorption of $\mathrm{Pb}$ (II). This is sustained by the good compliance with Halsey, Redlich-Peterson and Hill isotherms and their heterogeneity parameters (when it is the case) bellow unity.

The Rb19 equilibrium data complies with the nonlinear isotherms in the following order: Hill > Langmuir $>$ Sips $\approx$ Redlich-Peterson $\approx$ Toth $\approx($ Hill for $h=1)>$ modified BET $>$ Temkin $>$ Halsey $\approx$ Freundlich > Harkins-Jura. The compliance with both Hill and Langmuir isotherm indicates that there was a monolayer sequential biosorption of Rb19 dye and a homogeneous distribution of active sites on the surface of the RS-Pb biosorbent. The prevalence of Langmuir-type biosorption is marked by the 
equality with unity of the exponents of Sips, Redlich-Peterson and Toth equations. Moreover, it can be observed from Figure $4 \mathrm{~b}$ that these three-parameter isotherms overlapped each other, having the same $R^{2}$ and $\chi^{2}$ (Table 3). It is also the same for the special case when the Hill equation is reduced to Langmuir isotherm, i.e. $h=1$. According to Langmuir isotherm (Table 2), the monolayer biosorption capacity is $19.93 \mathrm{mg} / \mathrm{g}$. However, from the Hill equation a saturation capacity of $11.62 \mathrm{mg} / \mathrm{g}$ was obtained. More experiments should be made at higher concentrations, in order to establish the experimental saturation capacity.

\section{Conclusions}

The sequential biosorption of $\mathrm{Pb}(\mathrm{II})$ and Reactive blue 19 dye on rapeseed waste has been studied from 2 points of view: (1) the influence of the tested pollutants initial concentrations; (2) the compatibility of the obtained equilibrium data with five two-parameter and five three-parameter isotherm models. The initial concentration has a positive effect in both cases under study, the sequential biosorption capacity increasing with the increase in concentration. Compared to the individual biosorption of each target pollutant on pristine RS, an inhibition of the sequential biosorption of lead ions was observed at higher initial concentrations, whereas the uptake of the blue dye seemed to have improved slightly. The comparison between the linear and nonlinear forms of the highly popular Langmuir isotherm indicated that the nonlinear model presents a better way to determine the isotherm parameters. The derivation to obtain the linear equations influences the estimation of parameters. In case of Freudlich isotherm linear vs. non-linear comparison, the results weren't significantly different. The separation factor determined from Langmuir isotherm suggested that lead ions, as well as anionic dye, sequential biosorption was in favourable region $\left(R_{\mathrm{L}}<1\right)$. Based on the data obtained from the nonlinear regression error analysis, Freundlich isotherm proved to be valid for the observed equilibrium data of $\mathrm{Pb}$ (II) sequential biosorption, which takes place with relative difficulty ( $n$ between 1 and 2). Among the three-parameter isotherms, Halsey model, assuming multilayer and heterogeneous sorption, was found to provide the closest fit to the equilibrium data. Sequential biosorption data for Rb19 dye can be represented by Hill and Langmuir nonlinear isotherms, both describing a homogeneous biosorption system. Furthermore, Sips, Redlich-Peterson and Toth isotherms reduced to Langmuir equations as their exponential parameter equalled unity. Further work to establish the saturation concentration in the laboratory should be undertaken to elucidate between the Hill and Langmuir saturation biosorption capacity. The data provided by this study can be significant for the practical applicability assessment of the sequential sorption systems in water treatment and pollution control.

Acknowledgment: This work was supported by a grant of the Romanian Ministry of Research and Innovation, CCCDI-UEFISCDI, project number 26PCCDI/01.03.2018, "Integrated and sustainable processes for environmental clean-up, wastewater reuse and waste valorisation" (SUSTENVPRO), within PNCDI III.

\section{References}

1. ALALWAN, H.A., KADHOM, M.A., ALMINSHID, A.H., Removal of heavy metals from wastewater using agricultural byproducts, J. Water Supply Res. Technol., 69, 2020, 99-112. https://doi.org/10.2166/aqua.2020.133.

2. ZHOU, Y., LU, J., ZHOU, Y., LIU, Y., Recent advances for dyes removal using novel adsorbents: A review, Environ. Pollut., 252, 2019, 352-365. https://doi.org/10.1016/j.envpol.2019.05.072.

3. TAVAKOLIAN, M., WIEBE, H., SADEGHI, M.A., VAN DE VEN, T.G.M., Dye Removal Using Hairy Nanocellulose: Experimental and Theoretical Investigations, ACS Appl. Mater. Interfaces, 12, 2020, 5040-5049. https://doi.org/10.1021/acsami.9b18679.

4. SINGH, S., KUMAR, V., DATTA, S., DHANJAL, D.S., SHARMA, K., SAMUEL, J., SINGH, J., Current advancement and future prospect of biosorbents for bioremediation, Sci. Total Environ., 
709, 2020, 135895. https://doi.org/10.1016/j.scitotenv.2019.135895.

5. CRINI, G., LICHTFOUSE, E., WILSON, L.D., MORIN-CRINI, N., Conventional and nonconventional adsorbents for wastewater treatment, Environ. Chem. Lett., 17, 2019, 195-213. https://doi.org/10.1007/s10311-018-0786-8.

6. DE FREITAS, G.R., DA SILVA, M.G.C., VIEIRA, M.G.A., Biosorption technology for removal of toxic metals: a review of commercial biosorbents and patents, Environ. Sci. Pollut. Res., 26, 2019, 19097-19118. https://doi.org/10.1007/s11356-019-05330-8.

7. AFROZE, S., SEN, T.K., A Review on Heavy Metal Ions and Dye Adsorption from Water by Agricultural Solid Waste Adsorbents, Water, Air, Soil Pollut., 229, 2018, 225.

https://doi.org/10.1007/s11270-018-3869-z.

8. ADELAJA, O.A., BANKOLE, A.C., OLADIPO, M.E., LENE, D.B., Biosorption of $\mathrm{Hg}(\mathrm{II})$ ions, Congo red and their binary mixture using raw and chemically activated mango leaves, Int. J. Energy Water Resour., 3, 2019, 1-12. https://doi.org/10.1007/s42108-019-00012-0.

9. VISA, M., CHELARU, A.M., Hydrothermally modified fly ash for heavy metals and dyes removal in advanced wastewater treatment, Appl. Surf. Sci., 303, 2014, 14-22.

https://doi.org/10.1016/j.apsusc.2014.02.025.

10. GULER, U.A., SARIOGLU, M., Mono and binary component biosorption of $\mathrm{Cu}(\mathrm{II}), \mathrm{Ni}(\mathrm{II})$, and Methylene Blue onto raw and pretreated S. cerevisiae: Equilibrium and kinetics, Desalin. Water Treat., 52(25-27), 2014, 4871-4888. https://doi.org/10.1080/19443994.2013.810359.

11. ZHANG, R., ZHOU, Y., GU, X., LU, J., Competitive Adsorption of Methylene Blue and Cu ${ }^{2+}$ onto Citric Acid Modified Pine Sawdust, CLEAN - Soil, Air, Water, 43, 2015, 96-103. https://doi.org/10.1002/clen.201300818.

12. GARRUDO-GUIRADO, M.I., BLANCO-FLORES, A., TOLEDO-JALDIN, H.P., SÁNCHEZMENDIETA, V., VILCHIS-NÉSTOR, A.R., Reuse of sustainable materials for xylenol orange dye and copper (II) ion ammoniacal removal, J. Environ. Manage., 206, 2018, 920-928. https://doi.org/10.1016/j.jenvman.2017.11.074.

13. TOFAN, L., PADURARU, C., VOLF, I., TOMA, O., Waste of Rapeseed From Biodiesel Production As a Potential Biosorbent for Heavy Metal Ions, Bioresources, 6, 2011, 3727-3741. https://www.ncsu.edu/bioresources/BioRes_06/BioRes_06_4_3727_Tofan_PVT_Waste_Rapeseed_Bi odiesel_Sorb_Metal_Ions_1927.pdf.

14. MOROSANU, I., GILCA, A.F., PADURARU, C., FIGHIR (ARSENE), D., PEPTU, C.A., TEODOSIU, C., Valorisation of rapeseed as biosorbent for the removal of textile dyes from aqueous effluents, Cellul. Chem. Technol., 51, 2017, 175-184.

15. MOROSANU, I., TEODOSIU, C., PADURARU, C., IBANESCU, D., TOFAN, L., Biosorption of lead ions from aqueous effluents by rapeseed biomass, N. Biotechnol., 39, 2017, 110-124. https://doi.org/10.1016/j.nbt.2016.08.002.

16. MOROSAnU, I., TeOdosiU, C., COROABA, A., PADURARU, C., Sequencing batch biosorption of micropollutants from aqueous effluents by rapeseed waste: Experimental assessment and statistical modelling, J. Environ. Manage., 230, 2019, 110-118.

https://doi.org/10.1016/j.jenvman.2018.09.075.

17. JIAO, X., ZHANG, L., QIU, Y., YUAN, Y., A new adsorbent of $\mathrm{Pb}(\mathrm{II})$ ions from aqueous solution synthesized by mechanochemical preparation of sulfonated expanded graphite, $R S C A d v ., 7$, 2017, 38350-38359. https://doi.org/10.1039/C7RA05864K.

18. FREUNDLICH, H., Über die Adsorption in Lösungen, Zeitschrift Für Phys. Chemie, 57U, 1907, 385-471. https://doi.org/10.1515/zpch-1907-5723.

19. LANGMUIR, I., The constitution and fundamental properties of solids and liquids. Part I. Solids., J. Am. Chem. Soc., 38(11), 1916, 2221-2295. https://doi.org/10.1021/ja02268a002.

20. HALSEY, G., Physical adsorption on non-uniform surfaces, J. Chem. Phys., 16, 1948, 931-937. https://doi.org/10.1063/1.1746689.

21. TEMKIN, M., PYZHEV, V., Kinetics of ammonia synthesis on promoted iron catalysts, Acta 
Physicochim. URSS, 12, 1940, 217-222.

22. HARKINS, W.D., JURA, G., Surfaces of solids. XII. An absolute method for the determination of the area of a finely divided crystalline solid, J. Am. Chem. Soc., 66(8), 1944, 1362-1366. https://doi.org/10.1021/ja01236a047.

23. SIPS, R., On the structure of a catalyst surface, J. Chem. Phys., 16(5), 1948, 490-495. https://doi.org/10.1063/1.1746922.

24. REDLICH, O., PETERSON, D.L., A useful adsorption isotherm, J. Phys. Chem., 63(6), 1959, 1024-1024. https://doi.org/10.1021/j150576a611.

25. TÓTH, J., Adsorption : theory, modeling, and analysis, Marcel Dekker, New York, 2002.

26. EBADI, A., SOLTAN MOHAMMADZADEH, J.S., KHUDIEV, A., What is the correct form of BET isotherm for modeling liquid phase adsorption?, Adsorption, 15, 2009, 65-73. https://doi.org/10.1007/s10450-009-9151-3.

27. HILL, A., The possible effects of the aggregation of the molecules of haemoglobin on its dissociation curves, J. Physiol., 40, 1910, i-vii. https://doi.org/10.1113/jphysiol.1910.sp001386.

28. TRAN, H.N., YOU, S.-J., HOSSEINI-BANDEGHARAEI, A., CHAO, H.-P., Mistakes and inconsistencies regarding adsorption of contaminants from aqueous solutions: A critical review, Water Res., 120, 2017, 88-116. https://doi.org/10.1016/j.watres.2017.04.014.

29. AYAWEI, N., EBELEGI, A.N., WANKASI, D., Modelling and Interpretation of Adsorption Isotherms, J. Chem., 2017, 2017, 1-11. https://doi.org/10.1155/2017/3039817.

30. AL-GHOUTI, M.A., DA'ANA, D.A., Guidelines for the use and interpretation of adsorption isotherm models: A review, J. Hazard. Mater., 393, 2020, 122383.

https://doi.org/10.1016/j.jhazmat.2020.122383.

31. WEBER, T.W., CHAKRAVORTI, R.K., Pore and solid diffusion models for fixed-bed adsorbers, AIChE J., 20, 1974, 228-238. https://doi.org/10.1002/aic.690200204.

32. GUARÍN-ROMERO, J.R., RODRÍGUEZ-ESTUPIÑÁN, P., GIRALDO, L., MORENOPIRAJÁN, J.C., Simple and Competitive Adsorption Study of Nickel(II) and Chromium(III) on the Surface of the Brown Algae Durvillaea antarctica Biomass, ACS Omega, 4, 2019, 18147-18158. https://doi.org/10.1021/acsomega.9b02061.

33. BENI, A.A., ESMAEILI, A., Biosorption, an efficient method for removing heavy metals from industrial effluents: A Review, Environ. Technol. Innov., 17, 2020, 100503.

https://doi.org/10.1016/j.eti.2019.100503.

34. CHEN, C., Evaluation of Equilibrium Sorption Isotherm Equations, Open Chem. Eng. J., 7, 2013, 24-44. https://doi.org/10.2174/1874123101307010024.

35. SAADI, R., SAADI, Z., FAZAELI, R., FARD, N.E., Monolayer and multilayer adsorption isotherm models for sorption from aqueous media, Korean J. Chem. Eng., 32, 2015, 787-799. https://doi.org/10.1007/s11814-015-0053-7.

36. SHANMUGAPRAKASH, M., SIVAKUMAR, V., Batch and fixed-bed column studies for biosorption of $\mathrm{Zn}(\mathrm{II})$ ions onto pongamia oil cake (Pongamia pinnata) from biodiesel oil extraction, $J$. Environ. Manage., 164, 2015, 161-170. https://doi.org/10.1016/j.jenvman.2015.08.034.

37. SONG, C., WU, S., CHENG, M., TAO, P., SHAO, M., GAO, G., Adsorption Studies of Coconut Shell Carbons Prepared by $\mathrm{KOH}$ Activation for Removal of Lead(II) From Aqueous Solutions, Sustainability, 6, 2013, 86-98. https://doi.org/10.3390/su6010086.

38. KARA, A., KILIÇ, M., TEKIN, N., DINIBÜTÜN, N., ŞAFAKLI, A., Application of SepiolitePoly(vinylimidazole) composite for the removal of $\mathrm{Cu}(\mathrm{II})$ : Thermodynamics and isotherm studies, Int. J. Chem. Technol., 2, 2018, 20-33.

39. NAKKEERAN, E., SARANYA, N., GIRI NANDAGOPAL, M.S., SANTHIAGU, A., SELVARAJU, N., Hexavalent chromium removal from aqueous solutions by a novel powder prepared from Colocasia esculenta leaves, Int. J. Phytoremediation, 18, 2016, 812-821.

https://doi.org/10.1080/15226514.2016.1146229.

40. RANGABHASHIYA, S., SUJATA, L., BALASUBRAMANIAN, P., Biosorption characteristics 
of methylene blue and malachite green from simulated wastewater onto Carica papaya wood biosorbent, Surfaces and Interfaces, 10, 2018, 197-215. https://doi.org/10.1016/j.surfin.2017.09.011. 41. BASAR, C., Applicability of the various adsorption models of three dyes adsorption onto activated carbon prepared waste apricot, J. Hazard. Mater., 135, 2006, 232-241.

https://doi.org/10.1016/j.jhazmat.2005.11.055.

42. TZABAR, N., TER BRAKE, H.J.M., Adsorption isotherms and Sips models of nitrogen, methane, ethane, and propane on commercial activated carbons and polyvinylidene chloride, Adsorption, 22, 2016, 901-914. https://doi.org/10.1007/s10450-016-9794-9.

43. PADMESH, T.V.N., VIJAYARAGHAVAN, K., SEKARAN, G., VELAN, M., Application of Two-and Three-Parameter Isotherm Models: Biosorption of Acid Red 88 onto Azolla microphylla, Bioremediat. J., 10, 2006, 37-44. https://doi.org/10.1080/10889860600842746.

44. HO, Y.S., PORTER, J.F., MCKAY, G., Equilibrium isotherm studies for the sorption of divalent metal ions onto peat: Copper, nickel and lead single component systems, Water. Air. Soil Pollut., 141, 2002, 1-33. https://doi.org/10.1023/A:1021304828010.

45. RINGOT, D., LERZY, B., CHAPLAIN, K., BONHOURE, J., AUCLAIR, E., LARONDELLE, Y., In vitro biosorption of ochratoxin A on the yeast industry by-products: Comparison of isotherm models, Bioresour. Technol., 98(9), 2007, 1812-1821. https://doi.org/10.1016/j.biortech.2006.06.015.

Manusceipt receied: 10.05 .2020 